\title{
Lymph node metastases in gastric cancer
}

This issue has been specifically focused on the impact of lymph node metastases on staging ( $\mathrm{N}$ parameter), treatment planning and prognosis of gastric cancer patients.

Since nodal involvement still represents a real challenge for surgeons and oncologists, as well as radiologists/ gastroenterologists and pathologists, this topic will be widely discussed at the 12th International Gastric Cancer Congress scheduled for next April in Beijing.

The articles that you will read in the following pages cover all of the aspects related to relevance of a possible nodal disease associated with gastric cancer. Apart from the anatomical descriptions and classifications, a critical view with technical considerations about nodal status in terms of preoperative (as well as pathological) staging, surgical dissection and prognostic implications has been provided by well-known experts of the Italian Research Group for Gastric Cancer (GIRCG) along with some international guest authors (from Brazil, Germany and Greece).

The attempt to clarify one of the most controversial issues in gastric cancer management, strongly affecting the last 20 years literature, has been satisfied: the final result is a careful review of the state of the art with some intriguing prospective suggestions.

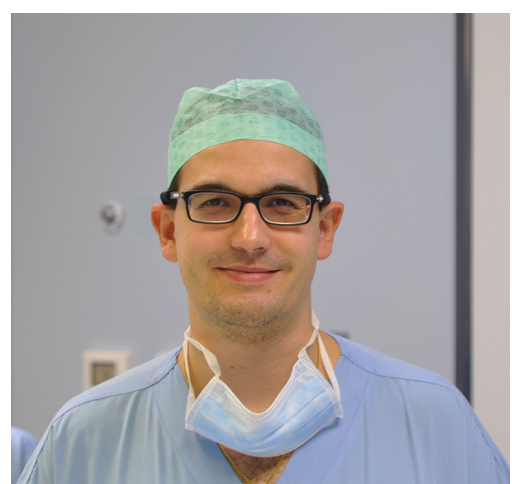

Stefano Rausei, $\mathrm{MD}, \mathrm{PhD}$

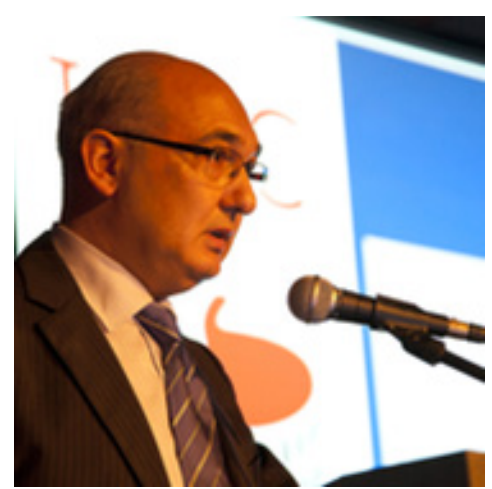

Daniele Marrelli, MD

Stefano Rausei, MD, PhD Surgical Assistant, Department of Surgery, University of Insubria, Varese, Italy. (Email: stefano.rausei@asst-settelagbi.it) Daniele Marrelli, MD Associate Professor, Unit of Surgical Oncology, University of Siena, Siena, Italy. (Email: daniele.marrelli@unisi.it) doi: $10.21037 /$ tgh.2017.01.09

Conflicts of Interest: The authors have no conflicts of interest to declare. View this article at: http://dx.doi.org/10.21037/tgh.2017.01.09

doi: $10.21037 / \operatorname{tgh} .2017 .01 .09$

Cite this article as: Rausei S, Marrelli D. Lymph node metastases in gastric cancer. Transl Gastroenterol Hepatol 2017;2:7. 